\title{
Sex ratio of transsexuals in Germany: the development over three decades
}

Garrels L, Kockott G, Michael N, Preuss W, Renter K, Schmidt G, Sigusch V, Windgassen K. Sex ratio of transsexuals in Germany: the development over three decades.

Acta Psychiatr Scand 2000: 102: 445-448. (C) Munksgaard 2000.

Objective: The higher incidence of man-to-woman transsexuals compared to woman-to-man transsexuals varies markedly from country to country. This is the first survey of the sex ratio to be made in Germany. Method: It covers 1785 patients who between 1964 and 1998 were diagnosed as transsexual at the four largest German centres offering treatment.

Results: From 1970 to 1994 the sex ratio remained constant at 2:1 in favour of man-to-woman transsexuals. Over the past 4 years, however, it has altered considerably and reached 1.2:1.

Conclusion: Up to 1994 our results do not support the assumption that transsexualism is gradually becoming equally prevalent in both sexes.

The drop in the sex ratio after 1994 can be explained either as a reduction of an overhang of male-to-female transsexuals or as an artificial phenomenon caused by recent developments in therapy and by the views of transsexuals' groups on the treatment they are offered.

\author{
L. Garrels ${ }^{1}$, G. Kockott ${ }^{2}$, \\ N. Michael ${ }^{3}$, W. Preuss ${ }^{4},{ }^{1}$ K. Renter ${ }^{4}$, \\ G. Schmidt ${ }^{4}$, V. Sigusch ${ }^{1}$, \\ K. Windgassen
}

${ }^{1}$ Institute for Sexual Science, University of Frankfurt/ Main, ${ }^{2}$ Psychiatric Clinic, Technical University Munich, ${ }^{3}$ Psychiatric Clinic, University of Münster, ${ }^{4}$ Department of Sexual Research, University of Hamburg, and ${ }^{5}$ Psychiatric Hospital 'Tannenhof', Remscheid, Germany

Key words: transsexualism; sex ratio; cross-cultural comparison

Lutz Garrels MD, Institute for Sexual Science, University of Frankfurt/Main, Theodor-Stern-Kai 7, D-60590 Frankfurt/Main, Germany

Accepted for publication June 22, 2000

\section{Introduction}

Scientific research into transsexualism has always reported a higher incidence of man-to-woman than woman-to-man transsexuals. This unexplained phenomenon, with marked variations from culture to culture, has prompted research in several countries; a survey will be presented in the discussion. In fact, the only reliable figures available, taken from large samples observed over a long period of time, come from Sweden and Holland. While in Holland the sex ratio has remained more or less stable at 3:1 for many years (1), more recent research in Sweden has shown a smaller difference between the sexes of about 1.4:1 $(2,3)$. Findings from the United States $(4,5)$, Canada (6) and Belgium (7) confirm that transsexualism is being found increasingly almost equally frequently in both sexes. In view of the lack of any reliable figures for Germany (West), the aim of our investigation was to discover whether there has been a similar reduction in the sex ratio here. To do this we examined all the 1785 patients who had been diagnosed as transsexual, using the
International Classification of Diseases (ICD) and Diagnostic and Statistical Manual (DSM), at the four largest centres in Germany. The time span covered was 1964-98.

\section{Material and methods}

In Germany a central register covering all transsexual patients such as the one in Sweden does not exist, nor is there one main centre for treating them. The large majority of patients, however, seek help in one of the few specialized university departments, as psychotherapists and experts in sexual medicine have only recently begun to treat these patients in their private practices. Four such specialized centres took part in this survey: the Department of Sex Research, University of Hamburg, the Institute for Sexual Science, University of Frankfurt/Main; the Psychiatric Clinic, University of Münster, and in Munich the Max-Planck-Institute for Psychiatry and the Psychiatric Clinic of the Technical University. Without exception, all the patients diag- 


\section{Garrels et al.}

nosed as transsexual according to ICD and DSM were included. Since some of the patients were seen only a few times, the diagnosis could not always be confirmed.

\section{Results}

Between 1964 and 1998 a total of 1785 transsexual patients were examined at the four centres (these began treating transsexuals at different dates). Since between 1964 and 1969 the total number of patients seen was very small, they have not been included in analysis by time. There is a brief description of the sample in Table 1. On average, man-to-woman transsexuals are 5 years older than woman-to-man transsexuals when they come for a first consultation. Currently, the patients in both groups are 2 or 3 years older when they first seek help than they were in the 1970s (Table 2).

Table 3 shows how the patients were distributed according to sex and locality. Taking in the whole 30 -year span covered by our investigation the sex ratio lies at 1.9:1. The differences between the various centres are only slightly significant $(P=0.08)$, which is due mainly to a low ratio in Munich. To analyse how the sex ratio altered over time, the total time span was divided into three steps of 10 years, from 1970 to 1998. For the period 1970-79 the sex ratio was 2.0:1, from 1980-89 2.2:1 but from 1990-98 as low as 1.6:1. Table 4 shows that it remained fairly constant for a long time, so the marked shift has taken place only during the past 4 years (1995-98 sex ratio 1.2:1). In absolute figures the number of man-to-woman transsexuals has fallen from 1995 to 1998, while the number of woman-to-man transsexuals has remained unchanged. The size of the shift varied from centre to centre, with Munich showing the biggest change; between 1995 and 1998 more womanto-man than man-to-woman transsexuals were seen there; but it is important to underline that the described drop in the sex ratio was not due to a change primarily in Munich. Munich excluded, from 1995 to 1998 the sex ratio was as similar as 1.3:1 in the remaining centres (compared to 1.2:1, Munich included).

Table 1. Description of samples

\begin{tabular}{lrrrrr}
\hline & & & \multicolumn{2}{c}{ Age at first consultation } \\
\cline { 4 - 6 } Locality & $N$ & First consultation & M & \multicolumn{1}{c}{ SD } & Range \\
\hline Hamburg & 815 & $1964-98$ & 30.7 & 9.9 & $14-79$ \\
Frankfurt am Main & 426 & $1975-98$ & 29.5 & 8.9 & $15-65$ \\
Munich & 383 & $1972-98$ & 31.4 & 10.5 & $15-78$ \\
Münster & 161 & $1986-97$ & 31.9 & 8.9 & $17-59$ \\
Total & 1785 & $1964-98$ & 30.7 & 9.7 & $14-79$ \\
\hline
\end{tabular}

Table 2. Age at first consultation (arithmetic mean in years) of male-to-female and female-to-male transsexuals by period

\begin{tabular}{lccc}
\hline Period & $\begin{array}{c}\text { Male-to-female } \\
n=1159\end{array}$ & $\begin{array}{c}\text { Female-to-male } \\
n=614\end{array}$ & $\begin{array}{c}\text { Total } \\
n=1773\end{array}$ \\
\hline $1970-79$ & 30.7 & 26.3 & 29.2 \\
$1980-89$ & 32.1 & 27.0 & 30.5 \\
$1990-98$ & 33.5 & 29.6 & 31.6 \\
Total & 32.3 & 27.6 & 30.7 \\
\hline
\end{tabular}

Significances (by ANOVA): sex $P<0.001$; period $P<0.001$; interaction of sex and period NS.

\section{Discussion}

In Table 5 the findings from previous surveys are summarized. Taken together the mean sex ratio for the 1950s and 1960s was 3.5:1 and for the 1970s and $1980 \mathrm{~s} 2.5: 1$ in favour of the man-to-woman transsexuals (leaving aside research into gender dysphoria, as this usually conceals other disorders). Taking into account the diversity of methods and standards applied and the sharp rise in the number of patients examined, the average sex ratio over 30 years reveals less difference between the sexes than has often been described in the literature. Nevertheless, the results from the first studies of transsexuals $(10,11,14-16)$ suggest that in the 'early days' until the 1960 s the patients seen were mainly man-towoman transsexuals. In the following two decades the ratio remained at about 2.5:1 (so far few figures are available from the 1990s). A recent study tends to confirm this figure for Holland (1). Other investigations in past years found the figures for the two sexes even closer $(2-5,7)$. If one takes only western countries into account, the range is reduced to between 1.4:1 and 3.0:1. So far there are no figures available for West Germany, apart from one set of findings where the results cannot be generally applied because of the special methods used (21).

Looking at the large number of patients included in this study, the homogeneous nature of the departments where they were treated and the similarity of our figures to those found by other methods (21), it is reasonable to assume that our sample is representative. As in Holland and Sweden, we can now trace

Table 3. Number of male-to-female and female-to-male transsexuals by localities

\begin{tabular}{lcccc}
\hline Locality & $\begin{array}{c}\text { Male-to- } \\
\text { female }\end{array}$ & $\begin{array}{c}\text { Female-to- } \\
\text { male }\end{array}$ & $\begin{array}{c}\text { \% Female-to- } \\
\text { male }\end{array}$ & Sex ratio \\
\hline Hamburg & 555 & 260 & 31.9 & $2.1: 1$ \\
Frankfurt am Main & 273 & 153 & 35.9 & $1.8: 1$ \\
Munich & 232 & 151 & 39.4 & $1.5: 1$ \\
Münster & 105 & 55 & 34.4 & $1.9: 1$ \\
Total & 1165 & 619 & 34.7 & $1.9: 1$ \\
\hline
\end{tabular}

Significance of differences between localities (by chi-quadrat): $P=0.08$. 
Table 4. Number of male-to-female and female-to-male transsexuals by 5-year periods

\begin{tabular}{lcccc}
\hline Period & Male-to-female & Female-to-male & \% Female-to-male & Sex ratio \\
\hline $1970-74$ & 74 & 26 & 26.0 & $2.8: 1$ \\
$1975-79$ & 176 & 101 & 36.5 & $1.7: 1$ \\
$1980-84$ & 201 & 98 & 32.8 & $2.1: 1$ \\
$1985-89$ & 273 & 117 & 30.0 & $2.3: 1$ \\
$1990-94$ & 271 & 136 & 33.4 & $2.0: 1$ \\
$1995-98$ & 164 & 136 & 45.3 & $1.2: 1$ \\
\hline
\end{tabular}

Significance of difference between 5-year-periods (by chi-quadrat) $P=0.001$.

changes reliably in the sex ratio of transsexuals in West Germany over a long period.

Just as in Holland and Sweden, we found that the sex ratio in West Germany remained more or less constant from 1970 to 1994; our figures show a sex ratio of 2.1:1 in favour of man-to-woman transsexuals, which is slightly lower than the Dutch figure (about 3:1) but markedly higher than the Swedish one (1.4:1). Taking the whole time span into account the sex ratio in Germany from 1970 to 1998 was 1.9:1. This figure is close to that found in Belgium (7) and in regional North American studies (4-6). The reasons for the divergences in the results probably lie in the varying methods and diagnostic procedures used, and in different sets of cultural assumptions in countries that are generally regarded as western. Ross et al. (19) showed comprehensively how cultural influences could explain differences in the sex ratio between Sweden and Australia.

It is, however, evident that over the past 4 years there has been a statistically significant drop in the sex ratio in Germany; it stands currently as low as $1.2: 1$. This change seems to be mainly the result of fewer man-to-woman transsexuals coming to our centres. Since there are no figures available from other countries for the very recent past it is hard to gauge whether this is a specifically German phenomenon. There are two possibilities to explain the changes since 1995 . The first is that since the last 4 years transsexualism in Germany is becoming more equally distributed between women and men. This could be due to a former overhang of male-to-female transsexuals that first during very recent years has been reduced. However, we do not have any reasonable explanation why this possible overhang should not have been reduced earlier.

The other possibility is that the described shift in the sex ratio is artificial. In our view this could be the outcome of two interlinked factors. On one hand, the situation for transsexuals seeking treatment has altered over the past few years with more psychotherapists now offering these patients help in their own practices. The second factor is that a critical discussion is under way among the transsexuals themselves about the treatment available and standards expected at our centres, with the result that certain patients go in search of other kinds of treatment that dispense with our standards. Based on a critical and controversial debate about our standards of care (e.g. 27, 28) we have gained the impression that this applies more to the man-to-woman transsexuals, which would fit with the reduced numbers we have been seeing recently.

Table 5. Sex ratio in former studies

\begin{tabular}{|c|c|c|c|c|c|}
\hline Country & Source & Time & $N$ total & SR & Calculation mode; notes \\
\hline Australia & (19) & Up to 1978 & 243 & $6.1: 1$ & Prevalence (by incidence 5:1) \\
\hline Belgium & (7) & 1986-94 & 35 & $1.7: 1$ & Own patients \\
\hline Canada & (6) & $1980-84$ & 197 & $1.7: 1$ & Own patients; gender dysphoria (!) \\
\hline Czechoslovakia & (20) & $1974-82$ & 94 & $1: 5.3$ & Own patients \\
\hline England & (8) & Up to 1959 & 30 & 2.3:1 & Own patients \\
\hline England (Wales) & (9) & 1958-68 & 66 & 3.3:1 & Prevalence, extrapolited from own patients \\
\hline Germany & (10) & Up to 1955 & 17 & - & Own patients; all male-to-female \\
\hline Germany & (11) & $1950-61$ & 41 & $7.2: 1$ & Own patients \\
\hline Germany (West) & (21) & 1981-90 & 1386 & 2.3:1 & Requests corresponding to transsex.-law \\
\hline Netherlands & (22) & 1976-86 & 538 & $3.0: 1$ & Own patients; (by prevalence 4.4:1) \\
\hline Netherlands & (23) & 1976-90 & 713 & 2.5:1 & Prevalence; following (22) \\
\hline Netherlands & (1) & $1975-92$ & 1285 & 2.8:1 & (corrected); own patients; following (22) and (23) \\
\hline Northern Ireland & (24) & $1967-81$ & 28 & $3.0: 1$ & Own patients \\
\hline Poland & (25) & $1974-80$ & 34 & $1: 5.5$ & Own patients (calculation unclear) \\
\hline Singapore & (26) & Up to 1986 & 458 & $3.0: 1$ & Prevalence \\
\hline Sweden & (12) & Up to 1965 & 110 & 2.8:1 & Prevalence \\
\hline Sweden & (13) & 1967-70 & 27 & $1.0: 1$ & Incidence \\
\hline Sweden & (3) & 1972-92 & 233 & $1.4: 1$ & Incidence (only primary form 1.0:1) \\
\hline USA & (14) & $1952-69$ & 439 & 7.4:1 & Own patients (up to 1964 6.4:1 (15), up to $19678.6: 1$ (16)) \\
\hline USA & (4) & $1970-83$ & 764 & $1.7: 1$ & Own patients; gender dysphoria () \\
\hline USA (Texas) & (5) & $1976-80$ & 90 & 2.0:1 & Own patients; gender dysphoria () \\
\hline International & (17) & $1916-65$ & 128 & $3.7: 1$ & Collected publications (Pauly 1968, 4:1 (18)) \\
\hline
\end{tabular}




\section{Garrels et al.}

To summarize, our results, at least for the period up to 1994, do not support the assumption that transsexualism is gradually becoming equally prevalent in both sexes. They support the finding that transsexualism in Europe and North America is 1.5 to 3 times more frequent in biological men than in biological women. In our view the shift in the sex ratio from 1995 to 1998 was due primarily to the different attitude of male-to-female transsexuals towards our treatment; if this is correct, further research is needed to show whether our results are replicated elsewhere and why male-tofemale transsexuals tend to resist German or other international standards of care. This information would be helpful to clinicians faced with an increasing number of male-to-female transsexuals refusing the treatment we currently offer.

\section{References}

1. Kesteren PJ van, Gooren LJ, Megens JA. An epidemiological and demographic study of transsexuals in the Netherlands. Arch Sex Behav 1996;25:589-598.

2. Landén M, WÅlinder J, Lundström B. Prevalence, incidence and sex ratio of transsexualism. Acta Psychiatr Scand 1996; 93:221-223

3. LANdÉn M, WÅlinder J, Lundström B. Incidence and sex ratio of transsexualism in Sweden. Acta Psychiatr Scand 1996;93:261-263.

4. Dixen JM, Madder H, Van Maasdam J, Edwards PW. Psychosocial characteristics of applicants evaluated for surgical gender reassignment. Arch Sex Behav 1984;13: 269-276.

5. Meyer WJ III, Webb A, Stuart CA, Finkelstein JW, Lawrence B, Walker PA. Physical and hormonal evaluation of transsexual patients: a longitudinal study. Arch Sex Behav 1986;15:121-138.

6. Blanchard R, Clemmensen LH, Steiner BW. Heterosexual and homosexual gender dysphoria. Arch Sex Behav 1987; 16:139-152.

7. De Cuypere G, Jannes C, Rubens R. Psychosocial functioning of transsexuals in Belgium. Acta Psychiatr Scand 1995;91: $180-184$.
8. Randell JB. Transvestitism and trans-sexualism. BMJ 1959; 2:1448-1452.

9. Hoenig J, Kenna JC. The prevalence of transsexualism in England and Wales. Br J Psychiatry 1974;124:181-190.

10. Overzier C. Beitrag zur Kenntnis des männlichen Transvestitismus. Z Psychother med Psychol 1955;5:152-168.

11. GiesE H. Psychopathologie der Sexualität. Stuttgart: Enke, 1962.

12. WÅLINDER J. Transsexualism: definition, prevalence and sex distribution. Acta Psychiatr Scand 1968;203:255-257.

13. WÅLINDER J. Incidence and sex ratio of transsexualism in Sweden. Br J Psychiatry 1971;119:195-196.

14. Benjamin H. Newer aspects of the transsexual phenomenon. J Sex Res 1969;5:135-144.

15. Benjamin H. Transsexualismus, Wesen und Behandlung. Nervenarzt 1964;35:499-500.

16. Benjamin H. Transvestitism and transsexualism in the male and female. J Sex Res 1967;3:107-127.

17. Pauly IB. Male psychosexual inversion: transsexualism. Arch Gen Psychiatry 1965;13:172-181.

18. Pauly IB. The current status of the change of sex operation. J Nerv Ment Dis 1968;147:460-471.

19. Ross MW, Wålinder J, Lundström B, Thuwe I. Crosscultural approaches to transsexualism. A comparison between Sweden and Australia. Acta Psychiatr Scand 1981;63: 75-82.

20. Brzek A, Sipová I. Transsexuelle in Prag. Sexualmedizin 1983;3:110-112.

21. Osburg S, Weitze C. Betrachtungen über zehn Jahre Transsexuellengesetz. Recht Psychiatrie 1993;11:94-107.

22. Eklund PLE, Gooren LJ, Bezemer PD. Prevalence of transsexualism in the Netherlands. Br J Psychiatry 1988;152:638640 .

23. Bakker A, Kesteren PJM van, Gooren LJG, Bezemer PD. The prevalence of transsexualism in the Netherlands. Acta Psychiatr Scand 1993;87:237-238.

24. O'Gorman EC. A retrospective study of epidemiological and clinical aspects of 28 transsexual patients. Arch Sex Behav 1982;11:231-236.

25. Godlewski J. Transsexualism and anatomic sex ratio reversal in Poland. Arch Sex Behav 1988;17:547-548.

26. Tsor WF. The prevalence of transsexualism in Singapore. Acta Psychiatr Scand 1988;78:501-504.

27. Lindemann G. Wieviel Ordnung muß sein? Z Sexualforsch 1997;10:324-331.

28. Transidentitas eV. Mehr Selbstbestimmung für transidentische Männer und Frauen! Z Sexualforsch 1997;10:342-350. 